\title{
Fine Mapping of the Ph-2 Gene Conferring Resistance to Late Blight (Phytophthora infestans) in Tomato
}

\author{
Xiaona Zhi, ${ }_{1}^{1}$ Jinshuai Shu, ${ }^{1}$ Zheng Zheng, ${ }^{2}$ Tao Li, ${ }^{1}$ Xiaorong Sun, ${ }^{1}$ Jinrui Bai, ${ }^{1}$ Yanan Cui, ${ }^{1}$ Xiaoxuan Wang, ${ }^{1}$ Zejun Huang, \\ Yanmei Guo, ${ }^{1}$ Yongchen Du, ${ }^{1}$ Yuhong Yang, ${ }^{1}$ Lei Liu, ${ }^{1, \dagger}$ and Junming $\mathrm{Li}^{1, \dagger}$ \\ ${ }^{1}$ Institute of Vegetables and Flowers, Chinese Academy of Agricultural Sciences, Beijing 100081, China \\ ${ }^{2}$ Institute of Industrial Crops, Henan Academy of Agricultural Sciences, Zhengzhou 450002, Henan, China
}

\begin{abstract}
Late blight is a devastating tomato disease. Breeding new varieties with multiple resistance $(R)$ genes is highly effective for preventing late blight. The $P h-2$ gene mediates resistance to Phytophthora infestans race $\mathrm{T}_{1}$ in tomato. In this study, we used an $\mathrm{F}_{2}$ population derived from a cross between Solanum lycopersicum Moboline (resistant) and LA3988 (suscep-

containing 21 projected genes, 5 of which were identified as putative $R$ genes. The Solyclog085460 coding sequence varied significantly between the parents. The markers developed and candidate genes identified in this study shall be useful for the molecular breeding of tomato exhibiting increased late blight resistance and for the cloning of the $P h-2$ gene.
\end{abstract} tible) cultivars for the fine mapping of $P h-2$. Two flanking markers, CAPS-1 and CC-Ase, mapped $P h-2$ to a $141-\mathrm{kb}$ genomic region
Keywords: candidate genes, fine mapping, late blight, $P h-2$, tomato
Tomato (Solanum lycopersicum L.) is an important economic crop worldwide. However, late blight epidemics caused by the oomycete Phytophthora infestans (Mont.) de Bary have adversely affected the global production of tomato (Ohlson and Foolad 2016). In 2007, late blight epidemics resulted in the loss of approximately 638,900 tons of tomato in Inner Mongolia, China (Li 2008). In 2009, the total tomato yield losses due to late blight reached $\$ 110$ million in the United States (Nowicki et al. 2012). Moreover, the financial losses associated with yield reductions and late blight control measures are estimated to exceed $\$ 5$ billion annually (Elsayed et al. 2012). Therefore, effective strategies for preventing late blight are required. Outbreaks of late blight can occur and spread rapidly, making them difficult to control. For many years, several fungicides have been widely used to prevent late blight (Fry 2016; Small et al. 2015); however, new $P$. infestans strains have emerged, with some resistant to the fungicides (Hu et al. 2012; Kirk et al. 2001). Consequently, late blight is increasingly becoming more difficult to control.

${ }^{\dagger}$ Corresponding authors: L. Liu; liulei02@ caas.cn; and J. Li; lijunming@caas.cn

\section{Zhi, J. Shu, and Z. Zheng contributed equally to this work.}

Funding: This work was supported by the National Natural Science Foundation of China (grant number 31401887), the National Key Research and Development Program of China (grant number 2016YFD0101703), the China Postdoctoral Science Foundation (2017M623289 and 2018T111123), the Fundamental Research Funds for Central Non-profit Scientific Institution (IVF-BRF2018006 and IVF-BRF2018007), the Key Laboratory of Biology and Genetic Improvement of Horticultural Crops, Ministry of Agriculture, China, and the Science and Technology Innovation Program of the Chinese Academy of Agricultural Sciences (grant number CAAS-ASTIPIVFCAAS).

*The $\boldsymbol{e}$-Xtra logo stands for "electronic extra" and indicates that a supplementary file and supplementary tables are published online.

The author(s) declare no conflict of interest.

Accepted for publication 2 October 2020.

(C) 2021 The American Phytopathological Society
Breeding new varieties with genetic resistance to $P$. infestans is the most effective way to minimize late-blight-caused losses. Thus, the effective use of new resistance $(R)$ genes by breeders is essential. The resistance to $P$. infestans is mediated by $R$ genes and several quantitative trait loci (QTLs). Over several decades, researchers have identified late blight $R$ genes, including $P h-1$, $P h-2, P h-3, P h-4$, and $P h-5$, in wild tomato species. The $P h-1$ gene, which confers complete resistance to $P$. infestans race $\mathrm{T}_{0}$, was mapped to the end of chromosome 7 (Bonde and Murphy 1952; Peirce 1971). The $P h-2$ gene, which was identified in S. pimpinellifolium 'West Virginia 700' (Gallegly and Marvel 1955), confers partial late blight resistance, which is useful for slowing the spread of the disease (Black et al. 1996a; Goodwin et al. 1995). The $P h-2$ gene was mapped to an 8.4-centimorgan (cM) region between markers CP105 and TG233 on chromosome 10 (Moreau et al. 1998). The $P h-3$ gene was identified in S. pimpinellifolium 'LA3708' (AVRDC 1994) and is a partially dominant gene located on the long arm of chromosome 9, where it encodes a coiled-coil nucleotide binding site leucine-rich repeat (CC-NBS-LRR) R protein (Black et al. 1996a,b; Chunwongse et al. 2002; Zhang et al. 2013, 2014). The $P h-4$ gene was detected in $S$. habrochaites 'LA1033' and was reported as a potential QTL (AVRDC 1998; Lough 2003). The $P h-5$ gene was identified in $S$. pimpinellifolium accession PI 270443, which is resistant to at least seven late blight pathogen races (Foolad et al. 2006). However, $P h-5$ is controlled by two sites, one on chromosome 1 (named $P h-5-1$ ) and one on chromosome 10 (named $P h-5-2$ ) (Merk and Foolad 2012; Merk et al. 2012; Nowicki et al. 2012), which has increased the difficulty of its application. Additionally, some late blight resistance QTLs have been identified in S. habrochaites (Brouwer et al. 2004; Chen et al. 2008; Li et al. 2011), S. cheesmaniae (Lukyanenko 1991), and S. pennellii (Smart et al. 2007). Unfortunately, introgressing these disease resistance QTLs into cultivated tomato plants requires more time, and many of them may be associated with undesirable traits (Brouwer et al. 2004). To date, the QTLs conferring late blight resistance have not been successfully applied to commercial production, and their practical value remains unknown (Foolad et al. 2014).

A previous study revealed that combining $P h-2$ and $P h-3$ results in resistance to the major $P$. infestans races in tomato (Foolad et al. 2006). Therefore, combining these two genes via molecular marker-assisted selection is an effective breeding strategy for improving tomato late blight resistance. Although 
$P h-3$ has been cloned, the lack of detailed information regarding $P h-2$, including its genomic location, has limited the development of molecular markers useful for the efficient selection of this gene. The objectives of this study were to (i) screen for markers linked to $P h-2$ and construct a high-resolution linkage map using the markers, (ii) analyze candidate $P h-2$ genes, and (iii) assess the accuracy and applicability of the developed markers using other tomato lines.

Table 1. Details regarding the markers associated with $P h-2$ on chromosome 10 of tomato and used in this study

\begin{tabular}{|c|c|c|c|}
\hline Marker name ${ }^{y}$ & Primer sequence $\left(5^{\prime}-3^{\prime}\right)^{\mathrm{z}}$ & Position in chromosome 10 (SL2.50) & Enzyme \\
\hline \multirow[t]{2}{*}{$\overline{\text { InDel-1 }}$} & F: CCTTTTCGAGAGTCAATCTG & $63,865,736-63,865,755$ & $\ldots$ \\
\hline & R: TGATGTGAGGAAGTGCTTTA & $63,865,852-63,865,833$ & $\ldots$ \\
\hline \multirow[t]{2}{*}{ InDel-2 } & F: CAGTACCTAACCACCATTGAA & $64,488,568-64,488,588$ & $\ldots$ \\
\hline & R: GCCGTTATTGAGGTTTATTG & $64,488,839-64,488,820$ & $\ldots$ \\
\hline \multirow[t]{2}{*}{ InDel-3 } & F: TTTGCACTCTATGATCACCA & $64,511,947-64,511,966$ & $\ldots$ \\
\hline & R: AACGGTGCTTGAACTGTATT & $64,512,173-64,512,154$ & $\ldots$ \\
\hline \multirow[t]{2}{*}{ InDel-4 } & F: TTGCTAACGAATTCCACTCT & $64,539,696-64,539,715$ & $\ldots$ \\
\hline & R: ATCAAACCCTAGCTATTCCA & $64,539,883-64,539,864$ & $\ldots$ \\
\hline \multirow[t]{2}{*}{ InDel-a } & F: TAAAGGGATGGTTTGTGGGGG & $64,543,045-64,543,065$ & $D d e \mathrm{I}$ \\
\hline & R: GGGTCCTTGTTTCTGAACTTAGAT & $64,543,140-64,543,117$ & $\ldots$ \\
\hline \multirow[t]{2}{*}{ CAPS-e } & F: ATTGCCAAATCTGGTACTCTGGT & $64,552,836-64,552,858$ & $B f a \mathrm{I}$ \\
\hline & R: CGGATAACAACCTGACAGCTCTA & $64,553,071-64,553,049$ & $\ldots$ \\
\hline \multirow[t]{2}{*}{ SNP-1 } & F: TCCAGATTCCCTCAGCATTCTTC & $64,552,871-64,552,893$ & $\ldots$ \\
\hline & R: CGGATAACAACCTGACAGCTCTA & $64,553,071-64,553,049$ & $\ldots$ \\
\hline \multirow[t]{4}{*}{ KASP-1 } & FAM: CAATTCCTACTTTGCACCAGCA & $64,552,952-64,552,972$ & $\ldots$ \\
\hline & HEX: ACAATTCCTACTTTGCACCAGCT & $64,552,951-64,552,973$ & $\ldots$ \\
\hline & Common: TGTGCTTAATTCTA & $64,553,025-64,552,997$ & $\ldots$ \\
\hline & TAAATGACAAAAACT & & \\
\hline \multirow[t]{2}{*}{ InDel-b } & F: TTCATGTACGTTGTTACAATAATCT & $64,556,588-64,556,612$ & $\ldots$ \\
\hline & R: ATTGCATCTAGAACTCCGGTGTT & $64,556,827-64,556,805$ & $\ldots$ \\
\hline \multirow[t]{2}{*}{ InDel-c-1 } & F: TCATCCGTCAGAAATAACCCCA & $64,570,133-64,570,154$ & $\ldots$ \\
\hline & R: TGTAATGCCACACAAGCAGA & $64,570,310-64,570,291$ & $\ldots$ \\
\hline \multirow[t]{2}{*}{ InDel-c } & F: AAAAATTATCACTAAGAAGTTTGGT & $64,570,206-64,570,230$ & $\ldots$ \\
\hline & R: GTAATGCCACACAAGCAGAA & $64,570,309-64,570,290$ & $\ldots$ \\
\hline \multirow[t]{2}{*}{ InDel-d } & F: ACGTATCGCAGAAAGTTGTTGTG & $64,573,682-64,573,704$ & $\ldots$ \\
\hline & R: TTCTAGTGGCACAACAGCTGTTA & $64,573,956-64,573,934$ & $\ldots$ \\
\hline \multirow[t]{2}{*}{ CAPS-a } & F: TAGGGAGATAGGCGAGCAGG & $64,575,341-64,575,360$ & $\ldots$ \\
\hline & R: TTTGGTGAGTCCATGTGAGC & $64,575,566-64,575,547$ & $\ldots$ \\
\hline \multirow[t]{2}{*}{ InDel-e } & F: AATGCAACGGCTAATCAACACA & $64,576,952-64,576,973$ & $B f a \mathrm{I}$ \\
\hline & R: AAGCAAATGATTCACCGCAGA & $64,577,021-64,577,001$ & $\ldots$ \\
\hline \multirow[t]{2}{*}{ InDel-f } & F: ACATATAGCGATAATTCAGGTTAGA & $64,580,960-64,580,984$ & $\ldots$ \\
\hline & R: CATGCTATCATGTGCCTCTGTAAT & $64,581,230-64,581,207$ & $\ldots$ \\
\hline \multirow[t]{2}{*}{ InDel-g } & F: TGACTTACCCTCCTCTTATTAATAC & $64,581,949-64,581,973$ & $\ldots$ \\
\hline & R: AGAGGAAAGTGAAACTAGGAAGCT & $64,582,248-64,582,225$ & $\ldots$ \\
\hline \multirow[t]{2}{*}{ InDel-h } & F: TTTGGTTGCTTGCAATATTTCCT & $64,585,267-64,585,289$ & $\ldots$ \\
\hline & R: AGTGCGCTTTTAACACTTCAATT & $64,585,528-64,585,506$ & $\ldots$ \\
\hline \multirow[t]{2}{*}{ CAPS-b-1 } & F: GGCCGGTAGGAGCAACATT & $64,603,850-64,603,868$ & Tsp509I \\
\hline & R: TTTCGCTTAGCTCGATAGCA & $64,603,934-64,603,915$ & $\ldots$ \\
\hline CAPS-b-2 & F: GGCCGGTAGGAGCAACATTT & $64,603,850-64,603,869$ & $D d e I$ \\
\hline & R: AGTTGAATTTCGCTTAGCTCGAT & $64,603,941-64,603,919$ & $\ldots$ \\
\hline SNP-6 & F: GGCCGGTAGGAGCAACATTT & $64,603,850-64,603,869$ & $\ldots$ \\
\hline & R: AGTTGAATTTCGCTTAGCTCGAT & $64,603,941-64,603,919$ & $\ldots$ \\
\hline SNP-2 & F: TATTTCGTACAGGTTGGGAGAGG & $64,626,301-64,626,323$ & $\ldots$ \\
\hline & R: AAGGATCCTGCATATTGTTGGCT & $64,626,533-64,626,511$ & $\ldots$ \\
\hline CC-Ase & R: GCTGACCGACAAATTCTTTA & $64,627,112-64,627,131$ & AseI \\
\hline & F: TTATTGAGTGGAAGGGAGAT & $64,627,595-64,627,614$ & $\ldots$ \\
\hline InDel-i & F: GCCCAAACAAGAGAGGAACG & $64,633,429-64,633,448$ & $\ldots$ \\
\hline & R: GCGATTCAATCATAACGGTGCT & $64,633,716-64,633,695$ & $\ldots$ \\
\hline CAPS-d & F: TCAGAACATCCTAAAGCACCGT & $64,633,681-64,633,702$ & Hрy99I \\
\hline & R: GGTATGTGGGTTGCGGATCA & $64,633,988-64,633,969$ & $\ldots$ \\
\hline InDel-j & F: AGCACCGTTATGATTGAATCGC & $64,633,695-64,633,716$ & $\ldots$ \\
\hline & R: TCATGCCGATCAGCTTACCC & $64,633,971-64,633,952$ & $\ldots$ \\
\hline SNP-3-2 & F: AAGCACCGTTATGATTGAATCGC & $64,633,694-64,633,716$ & $\cdots$ \\
\hline & R: TGCCGATCAGCTTACCCTTTTTA & $64,633,968-64,633,946$ & $\ldots$ \\
\hline SNP-3-1 & F: CACCGTTATGATTGAATCGCACA & $64,633,697-64,633,719$ & $\ldots$ \\
\hline & R: TGCCGATCAGCTTACCCTTTTTA & $64,633,968-64,633,946$ & $\ldots$ \\
\hline CAPS-c & F: AGCACCGTTATGATTGAATCGC & $64,633,695-64,633,716$ & PsiI \\
\hline & R: TCATGCCGATCAGCTTACCC & $64,633,971-64,633,952$ & $\ldots$ \\
\hline
\end{tabular}

y InDel = insertion and deletion, CAPS = cleaved amplified polymorphic sequence, SNP = single-nucleotide polymorphism, and KASP = Kompetitive allelespecific PCR.

${ }^{\mathrm{z}} \mathrm{F}=$ forward primer and $\mathrm{R}=$ reverse primer. 


\section{Materials and Methods}

Plant materials. The resistant line S. lycopersicum 'Moboline' (accession number LA3152) containing the $P h-2$ gene (kindly provided by the Tomato Genetics Resource Center [TGRC] at the University of California, Davis, CA, U.S.A.) and the susceptible line $S$. lycopersicum LA3988 (an introgression line of S. habrochaites 'LA1777' and S. lycopersicum 'FM-6203', kindly provided by TGRC) were selected as parents. The $\mathrm{F}_{2}$ segregating population obtained from the Moboline and LA3988 hybridization contained 394 individuals and was used for fine mapping the $P h-2$ gene.

In all, 35 inbred lines were used to verify the accuracy of the molecular markers linked to $P h-2$ (Supplementary Table S1). Thirteen of these were kindly provided by TGRC, one of which contains $P h-2$ (https://tgrc.ucdavis.edu/). Six of the inbred lines were kindly provided by the Mountain Horticultural Crops Research and Extension Center (Mills River, NC, U.S.A.), including one carrying $P h-2$ (https://mountainhort.ces.ncsu.edu/). Five of the inbred lines were kindly provided by the Asian Vegetables Research and Development Center (Taiwan, China), one of which contains Ph-2 (https://avrdc.org/). The remaining 11 inbred lines were kindly provided by the Institute of Vegetables and Flowers, Chinese Academy of Agricultural Sciences.

DNA extraction and marker development. For both the parents and progenies, fresh leaves were collected from individual plants. Total genomic DNA was extracted according to the cetyltrimethylammonium bromide method (Fulton et al. 1995). The DNA concentration was adjusted to $40 \mathrm{ng} / \mu \mathrm{l}$ for a PCR.

In a previous study, $P h-2$ was localized to chromosome 10 between markers CP105 and TG233 (Moreau et al. 1998). The Primer 5.0 software (http://www.PremierBiosoft.com) was used to design cleaved amplified polymorphic sequence (CAPS) and insertion and deletion (InDel) markers targeting this interval based on the publicly available tomato genome resequencing data (https://solgenomics.net/). The primers were 14 to $28 \mathrm{bp}$ long, with annealing temperatures of
55 to $60^{\circ} \mathrm{C}$. The PCR products for the CAPS and InDel markers were 80 to 500 and 80 to $300 \mathrm{bp}$ long, respectively. All primers were synthesized by Sangon Biotech Co., Ltd. (Beijing, China).

To delimit the $P h-2$ candidate region, markers were developed based on the whole-genome resequencing data $(30 \times$ genome coverage) for S. lycopersicum 'Moboline' (resistant material) and the nearisogenic line S. lycopersicum 'Monalbo' (susceptible material; accession number LA2818, kindly provided by TGRC). The genomes were sequenced by Anoroda Gene Technology Co., Ltd. (Beijing, China). The integrity and purity of DNA samples were evaluated by $1 \%$ agarose gel electrophoresis, whereas the DNA concentration was determined with the Qubit 2.0 Fluorometer (Life Technologies Corporation, Carlsbad, CA, U.S.A.). The DNA samples were randomly broken into 350-bp fragments with the Covaris M220 ultrasonicator (Gene Company Limited, Beijing, China). Sequencing libraries were constructed with the TruSeq Library Construction Kit (Illumina, San Diego, CA, U.S.A.). After the cluster generation step, the libraries were sequenced with the Illumina HiSeq 2000 system, resulting in 150-bp paired-end reads. We obtained clean reads by removing the adapter reads as well as reads with $>10 \%$ unknown nucleotides and low-quality reads (i.e., reads with $>50 \%$ bases with a $\mathrm{Q}$ value $\leq 5$ ) from the raw data with FastQC (Andrews 2010) and Cutadapt (Martin 2011). The clean reads were mapped to the tomato Heinz 1706 reference genome (SL2.50 version) with the SOAP software. The SAMtools program (version 1.2) (Li et al. 2009) was used to sort reads, whereas Picard tools (version 1.13) (http://broadinstitute.github.io/ picard/) were applied to eliminate duplicate reads due to PCR. Subsequently, the Genome Analysis Toolkit (McKenna et al. 2010) and the HaplotypeCaller protocol were used for calling single-nucleotide polymorphisms (SNPs) and InDels via the local reassembly of haplotypes for populations. The insertion and deletion mutations were used to design InDel markers. Regarding the SNPs, the Lasergene software (DNAStar, Madison, WI, U.S.A.) was used to scan for specific restriction enzyme recognition sites to develop CAPS markers.

Table 1. (Continued from previous page)

\begin{tabular}{|c|c|c|c|}
\hline Marker name ${ }^{y}$ & Primer sequence $\left(5^{\prime}-3^{\prime}\right)^{\mathbf{z}}$ & Position in chromosome 10 (SL2.50) & Enzyme \\
\hline \multirow[t]{2}{*}{ SNP-4-2 } & F: AAGCACCGTTATGATTGAATCGC & $64,633,694-64,633,716$ & $\ldots$ \\
\hline & R: TGCCGATCAGCTTACCCTTTTTA & $64,633,968-64,633,946$ & $\ldots$ \\
\hline \multirow[t]{2}{*}{ SNP-4-1 } & F: CACCGTTATGATTGAATCGCACA & $64,633,697-64,633,719$ & $\ldots$ \\
\hline & R: TGCCGATCAGCTTACCCTTTTTA & $64,633,968-64,633,946$ & $\ldots$ \\
\hline \multirow[t]{2}{*}{ SNP-5 } & F: AGTCGAAATTCAAACATGTTCTCT & $64,641,874-64,641,897$ & $\ldots$ \\
\hline & R: TCCCAAAGCCTATCTATTTACGCA & $64,642,147-64,642,124$ & $\ldots$ \\
\hline \multirow[t]{2}{*}{ InDel-k-1 } & F: CGCCAACACCAACAACCAAA & $64,768,173-64,768,192$ & $\ldots$ \\
\hline & R: CGTGTTGGGTCAAACACATGG & $64,768,292-64,768,272$ & $\ldots$ \\
\hline \multirow[t]{2}{*}{ InDel-k-2 } & F: CATCAACTCCTAGTTTTCTTCTGAG & $64,768,040-64,768,064$ & $\ldots$ \\
\hline & R: CGTGTTGGGTCAAACACATGG & $64,768,292-64,768,272$ & $\ldots$ \\
\hline \multirow[t]{2}{*}{ CAPS-1 } & F: GTCAATAATTTTCAACCATAGAATGATT & $64,768,441-64,768,465$ & HinfI \\
\hline & R: TGACATGAGAAGGAAAAGACTTAAG & $64,768,745-64,768,721$ & $\ldots$ \\
\hline \multirow[t]{2}{*}{ InDel-A } & F: TAGTGGAGGTAGGATTAT & $64,877,340-64,877,357$ & $\ldots$ \\
\hline & R: AGTAAGACTAAAAGTGGAA & $64,877,545-64,877,527$ & $\ldots$ \\
\hline \multirow[t]{2}{*}{ InDel-B } & F: ATTCACTAGAAAGGGGACA & $64,913,905-64,913,923$ & $\ldots$ \\
\hline & R: TCGTTATTGGAGGATGG & $64,914,023-64,914,007$ & $\ldots$ \\
\hline \multirow[t]{2}{*}{ InDel-5 } & F: CCGAGATGAGAGATTATACCA & $64,944,482-64,944,502$ & $\ldots$ \\
\hline & R: CGTTAGGAAATCTTGTTTCG & $64,944,761-64,944,742$ & $\ldots$ \\
\hline \multirow[t]{2}{*}{ InDel-C } & F: CTTCCACGATTACACCT & $64,959,501-64,959,517$ & $\ldots$ \\
\hline & R: TAATTCGTTGCACCATA & $64,959,625-64,959,609$ & $\ldots$ \\
\hline \multirow[t]{2}{*}{ InDel-6 } & F: AGAGAAAGAAACAAATCCCC & $65,310,385-65,310,404$ & $\ldots$ \\
\hline & R: CTACAACATTGCACCAGCTA & $65,310,570-65,310,551$ & $\ldots$ \\
\hline \multirow[t]{2}{*}{ InDel-D } & F: CTTACСТTCTТCTCCAA & $65,346,520-65,346,536$ & $\ldots$ \\
\hline & R: CTTATTACCTTTACCAAA & $65,346,749-65,346,732$ & $\ldots$ \\
\hline \multirow[t]{2}{*}{ InDel-F } & F: TTGGATTATGTTGGGTAG & $65,390,746-65,390,763$ & $\ldots$ \\
\hline & R: CAGTTCCTTTAGGCTTT & $65,390,967-65,390,951$ & $\ldots$ \\
\hline \multirow[t]{2}{*}{ InDel-E } & F: CTCCAAACAAGGAAAGA & $65,411,709-65,411,725$ & $\ldots$ \\
\hline & R: ATGCCAAAGGGCTAAAA & $65,411,929-65,411,913$ & $\ldots$ \\
\hline
\end{tabular}


The remaining polymorphic SNPs were developed as Kompetitive allele-specific PCR markers. Details regarding the primers for the identified markers are listed in Table 1.

Inoculation and disease assay. The $P$. infestans race $\mathrm{T}_{1}$ isolate used as the inoculum can overcome the resistance mediated by $P h$ 1 but not the resistance due to $P h-2$. The isolate was stored in $15 \%$ dimethyl sulfoxide at $-80^{\circ} \mathrm{C}$ (Zhang et al. 2013). Before inoculating plants, the isolate was activated and propagated on the leaflets of susceptible line LA3988, as described by Foolad et al. (2014). Plants with five fully expanded leaves were then spray inoculated with a suspension comprising $2 \times 10^{4}$ sporangia/ml, after which they were incubated at $20 \pm 2{ }^{\circ} \mathrm{C}$ and $100 \%$ relative humidity in darkness. After $24 \mathrm{~h}$, the plants were maintained at $20 \pm 2^{\circ} \mathrm{C}$ and 70 to $90 \%$ relative humidity with a 12 -h photoperiod in a greenhouse (natural light intensity) for 7 days (Brouwer et al. 2004; Zhang et al. 2013).

Disease severity (DS) was rated 7 to 10 days after the inoculation using the following 0 -to- 6 scale: $0=$ no apparent symptoms; $1=1$ to $5 \%$ of the leaf area affected, with small lesions; $2=6$ to $15 \%$ affected, with restricted lesions; $3=16$ to $30 \%$ affected, with water-soaked flecks on the stem; $4=31$ to $60 \%$ affected, with a few stem lesions; $5=61$ to $90 \%$ affected, with expanding stem lesions; and $6=91$ to $100 \%$ affected, with a severely damaged stem or dead plants. Plants with a DS score of 0 to 4 were considered resistant, whereas those with a DS score of 5 to 6 were designated as susceptible (Zhang et al. 2013, 2014).

Genetic mapping. In total, 394 individuals of the $F_{2}$ segregating population were genotyped with 11 molecular markers to map the $P h$-2 gene. Polymorphic marker bands were distinguished as follows: maternal genotype (genotype a), paternal genotype (genotype b), heterozygous (genotype h), or missing data (genotype u). A genetic linkage map was constructed using JoinMap 4 (Van Ooijen 2006), with a minimum logarithm of odds threshold of 3.0. Specifically, the map order and genetic distances were estimated based on the maximum likelihood and Kosambi function (Kosambi 1943).
Candidate gene analysis. The number and annotation details of the genes in the $P h-2$ candidate interval were obtained from the Sol Genomics Network (https://solgenomics.net/jbrowse_solgenomics/?data $=$ data $\% 2 F j$ son $\% 2 F S L 2.50 \&$ loc $=$ SL2.50 $10 \%$

3A64570206..64768173\&tracks=DNA\%2Cgene_models\&highlight=).

Sequence alignment and prediction of the structure of the proteins encoded by candidate genes. The coding regions of the candidate genes differentially expressed between the resistant and susceptible materials were sequenced and aligned. The coding region of each candidate gene based on the Heinz 1706 genome was downloaded from the Sol Genomics Network (https://solgenomics.net/ search/locus). Sequencing primers were designed with the Primer 5.0 software (http://www.PremierBiosoft.com). The PCR products were 500 to $1,000 \mathrm{bp}$ and the adjacent amplified fragments overlapped by at least 90 bp. PCR products were sequenced by Sangon Biotech Co., Ltd. Sequences were aligned with MUSCLE (https:// www.ebi.ac.uk/Tools/msa/muscle/). Moreover, protein structures were predicted with the Conserved Domains program (https:// www.ncbi.nlm.nih.gov/Structure/cdd/wrpsb.cgi?).

Statistical analysis. Data were analyzed with Microsoft Excel. Additionally, the $\chi^{2}$ test was performed with SPSS 17.0 software (SPSS Inc, Chicago, IL, U.S.A.).

\section{Results}

Inheritance analysis of late blight resistance mediated by $\boldsymbol{P h}-\mathbf{2}$. In earlier investigations, $P h-2$ was described as a single, incompletely dominant gene for late blight resistance (Gallegly and Marvel 1955; Moreau et al. 1998). In this study, we assessed the severity of late blight in the parental lines as well as in the $F_{1}$ and $F_{2}$ populations. The resistant line Moboline either lacked lesions or had narrow restricted lesions (Fig. 1A), with a DS score of 1.25 (DS scores between 0 and 2, standard deviation $=0.55, n=20)$ (Fig. 1B). The susceptible LA3988 plants had extensive expanded lesions or were dead (Fig.
A

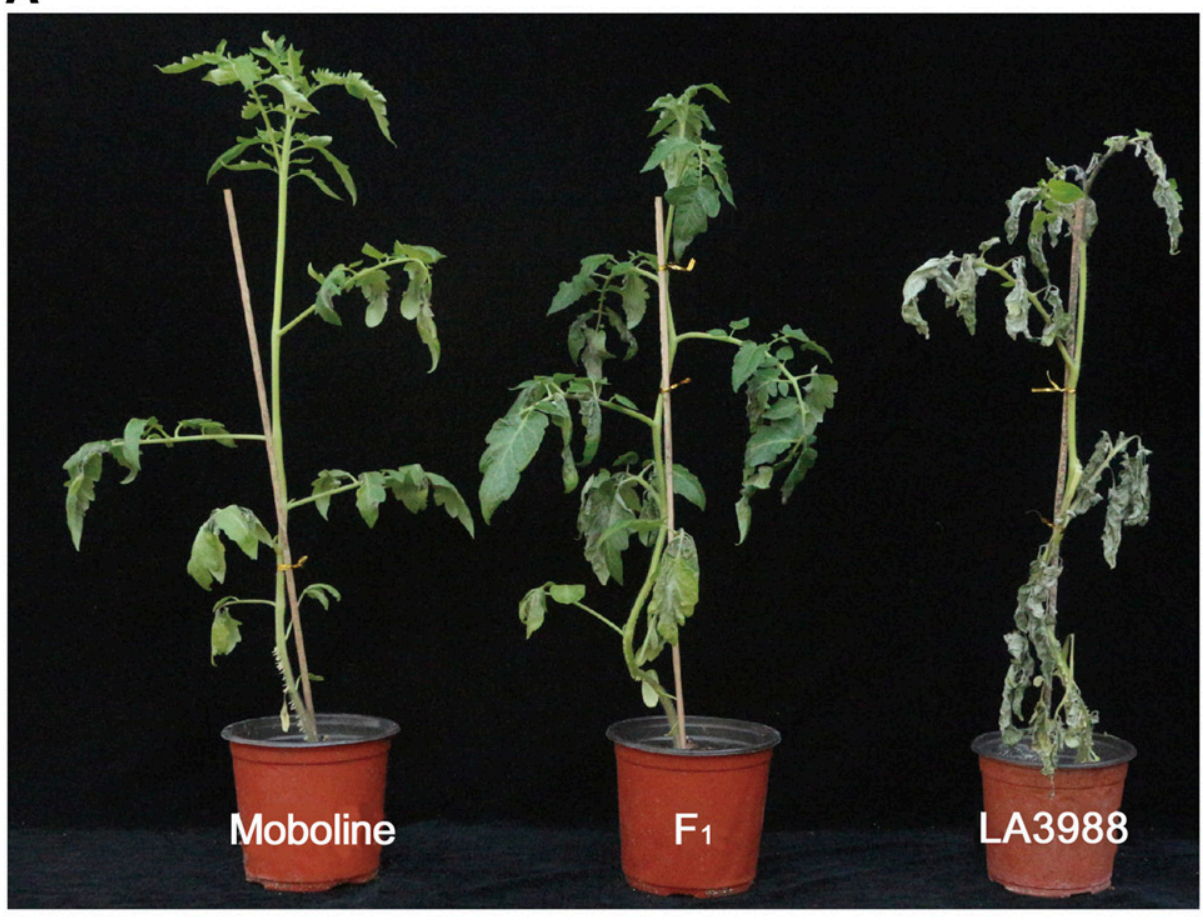

B

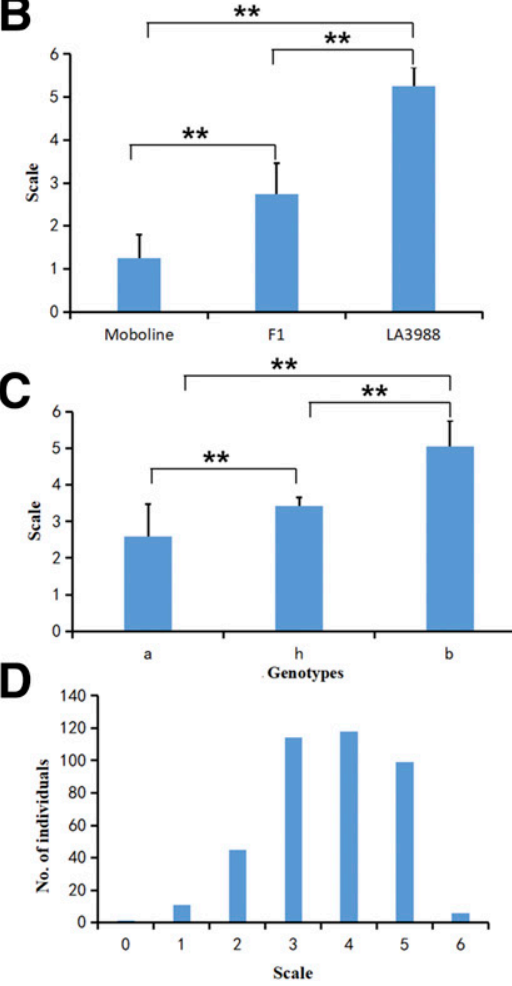

Fig. 1. Phenotypes of Moboline, $F_{1}$, and LA3988 plants 8 days after being inoculated with Phytophthora infestans and disease assays of the parental lines and the $F_{2}$ population. A, Phenotypes of Moboline, $F_{1}$, and LA3988 plants inoculated with $P$. infestans. B, Mean disease severity (DS) scores among Moboline, LA3988, and $F_{1}$ plants. C, Mean DS scores for $a, h$, and $b$ plants genotyped by the closest marker. D, Frequency distribution of the DS scores in the $F_{2}$ population. Asterisks ${ }^{* *}$ ) indicate $P<0.01$ based on Duncan's multiple range test. 
1A), with a DS score of 5.25 (DS scores between 5 and 6 , standard deviation $=0.44, n=20$ ) (Fig. 1B). These results confirmed that Moboline is significantly more resistant to late blight than LA3988 $(P<0.05)$. The $\mathrm{F}_{1}$ plants had an intermediate DS score of 2.75

(DS scores between 2 and 4 , standard deviation $=0.72, n=20$ )
(Fig. 1B), which was significantly different from the DS scores of either parent and the midparental value (DS score $=3.25$, standard deviation $=0.30, n=20)(P<0.05)$. These values were indicative of the incomplete dominance of $P h$-2. Analyses of the DS and genotype of 394 individuals of the $F_{2}$ population revealed that 88,202 , and 104

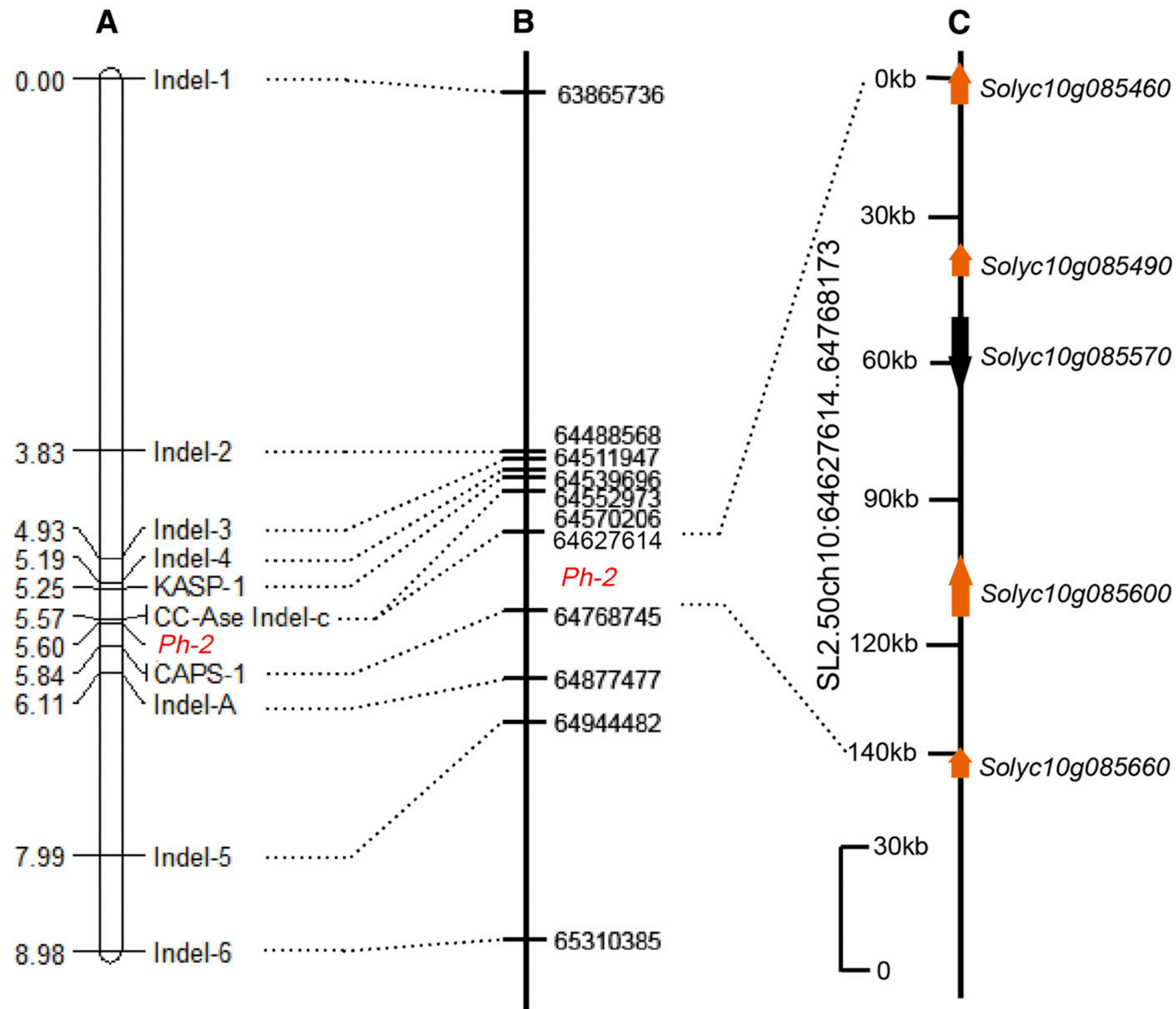

Fig. 2. Genetic and physical maps of $P h-2$. A, Genetic map of the Ph-2 locus. Indel = insertion and deletion, KASP = Kompetitive allele-specific PCR, and CAPS $=$ cleaved amplified polymorphic sequence. B, Physical fine mapping of $P h-2$. C, Five resistance genes in the $P h-2$ candidate region.

Table 2. Genotypes and phenotypes of recombinant individuals ${ }^{\mathrm{z}}$

\begin{tabular}{|c|c|c|c|c|c|c|}
\hline \multirow[b]{2}{*}{ Generation } & \multirow[b]{2}{*}{ Code } & \multicolumn{4}{|c|}{ Genotype } & \multirow[b]{2}{*}{ Phenotype } \\
\hline & & InDel-4 & KASP-1 & CC-Ase & CAPS-1 & \\
\hline \multirow{4}{*}{$\mathrm{F}_{2}$ recombinant individual } & A162 & $\mathrm{h}$ & $\mathrm{h}$ & $\mathrm{b}$ & $\mathrm{b}$ & $S$ \\
\hline & A236 & $\mathrm{b}$ & $\mathrm{b}$ & $\mathrm{b}$ & $\mathrm{h}$ & S \\
\hline & A283 & $\mathrm{h}$ & $\mathrm{h}$ & $\mathrm{h}$ & $\mathrm{b}$ & $\mathrm{R}$ \\
\hline & A 343 & $\mathrm{~h}$ & $\mathrm{~h}$ & $\mathrm{~h}$ & $\mathrm{~b}$ & $S$ \\
\hline \multirow[t]{3}{*}{$\mathrm{F}_{3}$ recombinant individual } & A343-23 & $\mathrm{a}$ & a & a & $\mathrm{b}$ & S \\
\hline & A283-8 & a & $\mathrm{a}$ & $\mathrm{a}$ & $\mathrm{b}$ & $\mathrm{R}$ \\
\hline & A162-14 & $\mathrm{a}$ & $\mathrm{a}$ & $\mathrm{b}$ & $\mathrm{b}$ & $S$ \\
\hline
\end{tabular}

${ }^{\mathrm{z}}$ InDel $=$ insertion and deletion, KASP $=$ Kompetitive allele-specific PCR, CAPS $=$ cleaved amplified polymorphic sequence, $\mathrm{a}=$ homozygous for the resistant parent Moboline, $\mathrm{b}=$ homozygous for the susceptible parent LA3988, $\mathrm{h}=$ heterozygous, $\mathrm{S}=$ susceptible, and $\mathrm{R}=$ resistant. 
individuals carried the $\mathrm{a}, \mathrm{h}$, and $\mathrm{b}$ genotypes, respectively. The mean DS scores for the $\mathrm{a}, \mathrm{h}$, and $\mathrm{b}$ genotypes were $2.59,3.43$, and 5.06, respectively. There were significant differences among these three genotypes $(P<0.05)$ (Fig. 1C). The $\chi^{2}$ test indicated that the segregation ratio of the $a, h$, and $b$ progenies was consistent with the expected ratio of $1: 2: 1\left(\chi^{2} 1: 2: 1=1.553, P=0.460\right)$. These results confirmed the incomplete dominance of the $P h-2$ gene.

Fine mapping of the $\boldsymbol{P h}-\mathbf{2}$ gene. In a previous study, $P h-2$ was mapped within an 8.4-cM region between markers CP105 and TG233 on chromosome 10 (Moreau et al. 1998). On the basis of the results of previous studies, 18 molecular markers were screened in a larger interval, 7 of which are polymorphic between the parental lines Moboline and LA3988 (Table 1). A linkage analysis of $394 \mathrm{~F}_{2}$ individuals identified InDel-4 and CAPS-1 as the nearest markers flanking the $P h-2$ locus, with an interval of $229 \mathrm{~kb}$ in the tomato Heinz 1706 reference genome (SL2.50 version) (Fig. 2A).

To narrow down the $P h-2$ candidate region, near-isogenic lines of Moboline (resistant line) and Monalbo (susceptible line) were sequenced (30x effective depth). In total, 54 SNPs and 60 InDels were detected in the $P h-2$ candidate region (Supplementary Table S2). On the basis of these polymorphisms, 35 new markers were designed, 4 of which were polymorphic between the parents of the fine-mapping population (Table 1). These four polymorphic markers were used to further delimit the fine mapped interval to a 141-kb region (Fig. 2B) in the reference genome between the CAPS-1 and CC-Ase markers (Fig. 2A). This result was confirmed by the phenotypes of the $\mathrm{F}_{3}$ progenies corresponding to three of the most informative $\mathrm{F}_{2}$ recombinants (Table 2).

$P h-2$ candidate gene analysis. The annotation of the $P h-2$ candidate region based on the fine-mapping data revealed 21 genes (Supplementary Table S3), including 5 putative $R$ genes (Fig. 2C), with 1 belonging to the NBS-LRR family (Solyc10g085460) and 4 encoding serine/threonine kinases (Solyc10g085570, Solyc10g085490, Sol$y c 10 g 085600$, and Solyc10g085660) (Table 3).

An alignment of the coding regions of the five projected $R$ genes indicated that only Solyc10g085460 varied between the parents (Supplementary File S1). The coding sequence of this putative gene comprises 3,687 bp, with 32 SNPs between Moboline and LA3988. Additionally, Solyclog085460 was predicted to encode a CCNBS-LRR protein consisting of 1,228 amino acids, of which 19 differ between Moboline and LA3988. The predicted protein structure suggested that these 19 amino acids are located in the LRR conserved domain and are associated with the diversity in the number of LRRs in Moboline (17 LRRs) and LA3988 (16 LRRs) (Fig. 3). Accordingly, Solyclog085460 is presumed to play a key role in the $P h-2$ mediated late blight resistance of tomato.

Verification of the accuracy of the molecular markers linked to $\boldsymbol{P h}$-2. The molecular markers linked to $P h$-2 (namely, InDel-1, InDel-2, InDel-3, InDel-4, InDel-c, CC-Ase, CAPS-1, and InDel6) were used to screen 35 tomato inbred lines (Supplementary Table S1). The InDel-4, InDel-c, and CAPS-1 markers correctly determined the $P h-2$ genotype of all 35 lines, with $100 \%$ accuracy (Fig. 4). In contrast, the InDel-1, InDel-2, InDel-3, CC-Ase, and InDel-6 markers were 91.43, 51.43, 40, 74.29, and 94.29\% accurate, respectively.

\section{Discussion}

Breeding resistant varieties is the most effective way to prevent late blight. Currently, $P h-2$ and $P h-3$ are the most widely used $R$ genes in commercial tomato cultivars. Newly emerging and more aggressive $P$. infestans strains are able to infect tomato plants carrying only one of these genes (Chunwongse et al. 2002; Foolad et al. 2008; Irzhansky and Cohen 2006). Researchers have confirmed that combining $P h-2$ and $P h-3$ can enhance the resistance to multiple races

Table 3. Annotated $P h-2$ candidate genes

\begin{tabular}{lcll}
\hline Gene name & Start & End & \multicolumn{1}{c}{ Annotation $^{\mathbf{z}}$} \\
\hline Solyc10g085460 (-) & $64,626,257$ & $64,630,102$ & CC-NBS-LRR resistance protein \\
Solyc10g085570(+) & $64,684,109$ & $64,697,016$ & CTR4 and its splice variants CTR4sv1 and -sv2 \\
Solyc10g085490 (-) & $64,643,337$ & $64,646,939$ & F-box protein PP2-B1 \\
Solyc10g085600 (-) & $64,715,492$ & $64,728,193$ & F-box/LRR-repeat protein 4 \\
Solyc10g085660 (-) & $64,768,049$ & $64,769,422$ & F-box protein SKIP24 \\
\hline
\end{tabular}

${ }^{\mathrm{z}}$ CC-NBS-LRR $=$ coiled-coil nucleotide binding site leucine-rich repeat.

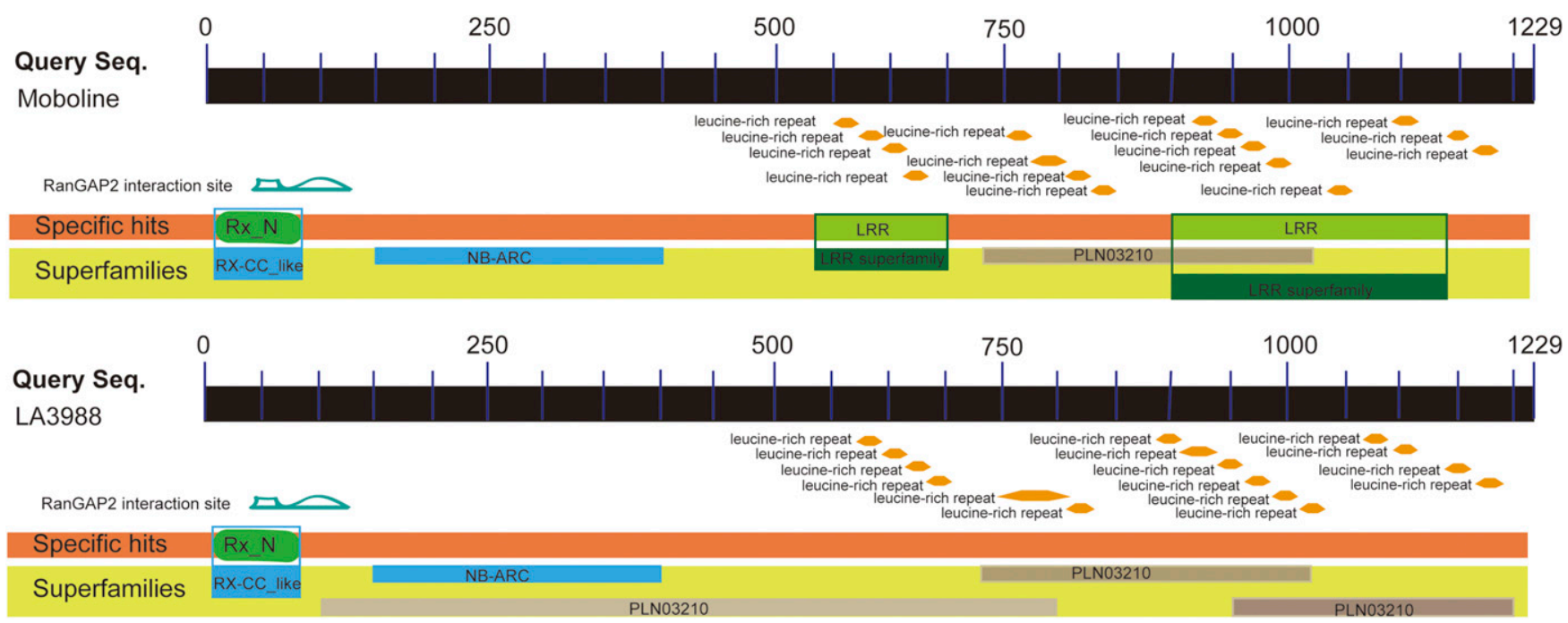

Fig. 3. Predicted structure of the protein encoded by Solyc10g085460 in Moboline and LA3988. NB-ARC = nucleotide-binding adaptor shared by APAF-1, R proteins, and CED-4 and LRR = leucine-rich repeat. 


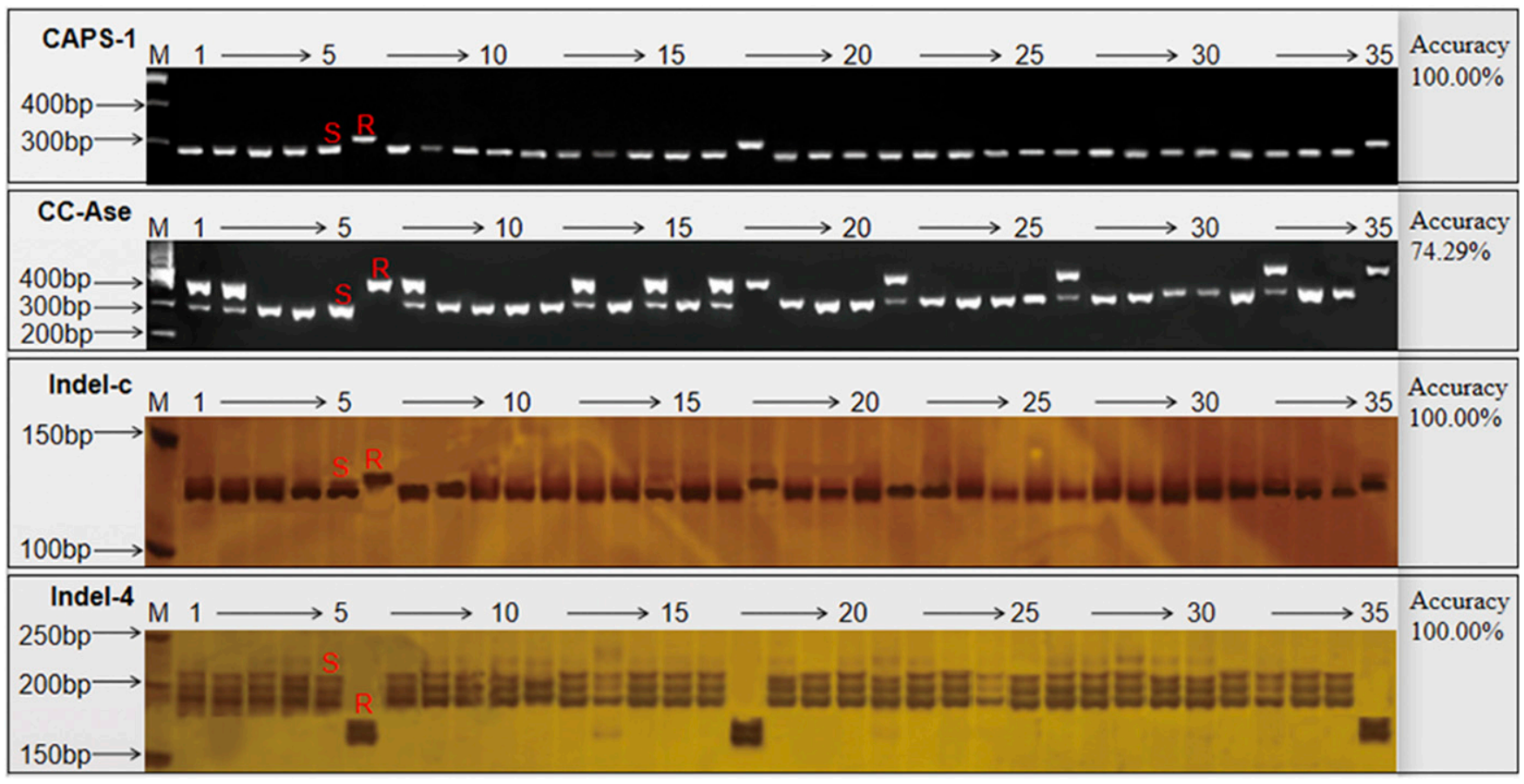

Fig. 4. Gel electrophoresis of molecular markers linked to $P h-2$ in 35 tomato inbred lines. $M=$ size marker; varieties as follows: lanes 1 to $5=$ N735, N736, 17-3051, NC25P, and 173052; lanes 6 to $10=$ NC2CECBR, 18-S88-1, NEBR-7, 18-S105-1, and NCEBR-8; lanes 11 to $15=18-S 120-1,18-S 87-1$, CLN3125A, 16-350-1, and CLN3078B; lanes 16 to 20 = 14-1772, CLN3241R, 18-S122-1, CLN2037E, and 18-S143-1; lanes 21 to $25=$ CLN2037B, 18-S71-1, Monalbo, E6203, and Moneymaker; lanes 26 to $30=$ M82, VFN8, H1706, Pearson, and CASTLEMART; lanes 31 to 35 = Momotaro, Ailsa Craig, Micro-Tom, KR1441,and Moboline; S contains ph-2 and R contains Ph-2.

(Gardner and Panthee 2010; Panthee and Gardner 2010). Pyramiding multiple $R$ genes to develop highly resistant varieties represents an effective strategy for minimizing late-blight-caused losses. The $P h-3$ gene has been cloned (Zhang et al. 2014) and the resistance conferred by this gene can be efficiently selected via marker-assisted selection (Robbins et al. 2010). However, $P h-2$ has not been cloned and its precise genomic position was unknown, making it challenging for researchers attempting to develop efficient molecular markers to improve selection efforts. To increase the utility of $P h-2$, we studied its inheritance and developed closely linked molecular markers.

A previous study revealed that $P h-2$ is located on the distal part of the long arm of chromosome 10 (Moreau et al. 1998). In this study, we used an $\mathrm{F}_{2}$ population developed from a cross between the lateblight-resistant line Moboline and the susceptible line LA3988 to fine map $P h-2$. Whole-genome resequencing facilitated the development of molecular markers saturating the $P h-2$ interval. We constructed a high-resolution genetic map with 11 polymorphic molecular markers. Moreover, $P h-2$ was localized to a $141-\mathrm{kb}$ interval $(64,627,614$ to $64,768,745$ bp) between markers CC-Ase and CAPS1 on chromosome 10 , corresponding to a genetic distance of $0.27 \mathrm{cM}$.

In plants, the largest $R$ gene family encodes NBS and LRR domains. Furthermore, 26 late-blight $R$ genes have been cloned in tomato and potato, 22 of which belong to the NBS-LRR $R$ gene family (Rodewald and Trognitz 2013; Xu and Jin 2017; Yue et al. 2012; Zhang et al. 2013). In this study, we detected 21 genes in the $P h-2$ candidate region but only Solyclog085460 belongs to the NBS-LRR gene family. A sequence analysis revealed differences in the Solyc10g085460 coding sequence between the resistant and susceptible materials, resulting in diverse protein structures. Therefore, our findings imply that Solyclog085460 may be the $P h-2$ gene or is possibly involved in the same pathway as $P h-2$ during responses to $P$. infestans.

In this study, the accuracy of the markers CC-Ase and InDel-c, which are closest to $P h$-2, were 74.29 and $100.00 \%$, respectively. Consequently, InDel-c may be useful for tomato breeders interested in developing new varieties carrying $P h-2$. However, very few resistant cultivars were tested using the newly developed markers in this study. Therefore, it may be necessary to verify the generality and the accuracy of the markers in a larger population in a future study.

\section{Acknowledgments}

We thank L. Bianji, Edanz Editing China (https://www.liwenbianji.cn/ac), for editing the English text of a draft of this manuscript.

\section{Literature Cited}

Andrews, S. 2010. FastQC: A Quality Control Tool for High Throughput Sequence Data. http://www.bioinformatics.babraham.ac.uk/projects/fastqc

AVRDC. 1994. Pages 201-203 in: 1993 Progress Report. Asian Vegetable Research and Development Center, Shanhua, Tainan, Taiwan.

AVRDC. 1998. Pages 9-13 in: AVRDC Report 1998. Asian Vegetable Research and Development Center, Shanhua, Tainan, Taiwan.

Black, L. L., Wang, T. C., Hanson, P., and Chen, J. T. 1996a. Late blight resistance in four wild tomato accessions: Effectiveness in diverse locations and inheritance of resistance. J. Phytopathol. 86:S24.

Black, L. L.. Wang, T. C., Hanson, P., and Chen, J. T. 1996b. New sources of late blight resistance identified in wild tomatoes. TVIS Newsl. 1:15-17.

Bonde, R., and Murphy, E. F. 1952. Resistance of certain tomato varieties and crosses to late blight. Maine. Agric. Exp. Stn. Bull. 497:5-15.

Brouwer, D. J., Jones, E. S., and St Clair, D. A. 2004. QTL analysis of quantitative resistance to Phytophthora infestans (late blight) in tomato and comparisons with potato. Genome 47:475-492.

Chen, C. H., Sheu, Z. M., and Wang, T. C. 2008. Host specificity and tomatorelated race composition of Phytophthora infestans isolates in Taiwan during 2004 and 2005. Plant Dis. 92:751-755.

Chunwongse, J., Chunwongse, C., Black, L., and Hanson, P. 2002. Molecular mapping of the $P h-3$ gene for late blight resistance in tomato. J. Hortic. Sci. Biotechnol. 77:281-286

Elsayed, A. Y., da Silva, D. J. H., Carneiro, P. C. S., and Mizubuti, E. S. G. 2012 The Inheritance of late blight resistance derived from Solanum habrochaites. Crop Breed. Appl. Biotechnol. 12:199-205.

Foolad, M. R., Merk, H. L., and Ashrafi, H. 2008. Genetics, genomics and breeding of late blight and early blight resistance in tomato. Crit. Rev. Plant Sci. 27:75-107.

Foolad, M. R., Merk, H. L., Ashrafi, H., and Kinkade, M. P. 2006. Identification of new sources of late blight resistance in tomato and mapping of a new resistance gene. Pages 4-7 in: 21st Annu. Tomato Dis. Workshop. North Carolina State University, North Carolina State University, Fletcher, NC, U.S.A.

Foolad, M. R., Sullenberger, M. T., Ohlson, E. W., and Gugino, B. K. 2014 Response of accessions within tomato wild species, Solanum pimpinellifolium to late blight. Plant Breed. 133:401-411.

Fry, W. E. 2016. Phytophthora infestans: New tools (and old ones) lead to new understanding and precision management. Annu. Rev. Phytopathol. 54:529-547.

Fulton, T. M., Chunwongse, J., and Tanksley, S. D. 1995. Microprep protocol for extraction of DNA from tomato and other herbaceous plants. Plant Mol. Biol Rep. 13:207-209. 
Gallegly, M. E., and Marvel, M. E. 1955. Inheritance of resistance to tomato race0 of Phytophthora infestans. J. Phytopathol. 45:103-109.

Gardner, R. G., and Panthee, D. R. 2010. NC 1 CELBR and NC 2 CELBR: Early blight and late blight-resistant fresh market tomato breeding lines. HortScience 45:975-976.

Goodwin, S. B., Sujkowski, L. S., and Fry, W. E. 1995. Rapid evolution of pathogenicity within clonal lineages of the potato late blight disease fungus. Phytopathology 85:669-676.

Hu, C. H., Perez, F. G., Donahoo, R., McLeod, A., Myers, K., Ivors, K., Secor, G., Roberts, P. D., Deahl, K. L., Fry, W. E., and Ristaino, J. B. 2012. Recent genotypes of Phytophthora infestans in the eastern United States reveal clonal populations and reappearance of mefenoxam sensitivity. Plant Dis. 96: 1323-1330.

Irzhansky, I., and Cohen, Y. 2006. Inheritance of resistance against Phytophthora infestans in Lycopersicon pimpenellifolium L3707. Euphytica 149:309-316.

Kirk, W. W., Felcher, K. J., Douches, D. S., Coombs, J., Stein, J. M., Baker, K. M., and Hammerschmidt, R. 2001. Effect of host plant resistance and reduced rates and frequencies of fungicide application to control potato late blight. Plant Dis. 85:1113-1118.

Kosambi, D. D. 1943. The estimation of map distances from recombination values. Ann. Eugen. 12:172-175.

Li, B. 2008. Reasons of late blight affecting processing tomato in Baynnur in 2007. China Veg. 8:59-60 (in Chinese).

Li, H., Handsaker, B., Wysoker, A., Fennell, T., Ruan, J., Homer, N., Marth, G., Abecasis, C., and Durbin, R. 2009. The sequence alignment/map format and SAMtools. Bioinformatics 25:2078-2079.

Li, J., Liu, L., Bai, Y., Finkers, R., Wang, F., Du, Y., Yang, Y., Xie, B., Visser, R. G. F., and van Heusden, A. W. 2011. Identification and mapping of quantitative resistance to late blight (Phytophthora infestans) in Solanum habrochaites LA1777. Euphytica 179:427-438.

Lough, R. C. 2003. Inheritance of tomato late blight resistance in Lycopersicon hirsutum LA1033. Ph.D. dissertation, North Carolina State University.

Lukyanenko, A. N. 1991. Disease resistance in tomato. Pages 99-119 in: Genetic Improvement of Tomato. G. Kalloo, ed. Monographs on Theoretical and Applied Genetics, vol. 14. Springer, Berlin, Heidelberg, Germany.

Martin, M. 2011. Cutadapt removes adapter sequences from high-throughput sequencing reads. EMBnet 17:10-12.

McKenna, A., Hanna, M., Banks, E., Sivachenko, A., Cibulskis, K., Kernytsky, A., Garimella, K., Altshuler, D., Gabriel, S., Daly, M., and DePristo, M. A. 2010. The Genome Analysis Toolkit: A MapReduce framework for analyzing next-generation DNA sequencing data. Genome Res. 20: 1297-1303

Merk, H. L., Ashrafi, H., and Foolad, M. R. 2012. Selective genotyping to identify late blight resistance genes in an accession of the tomato wild species Solanum pimpinellifolium. Euphytica 187:63-75.
Merk, H. L., and Foolad, M. R. 2012. Parent-offspring correlation estimate of heritability for late blight resistance conferred by an accession of the tomato wild species Solanum pimpinellifolium. Plant Breed. 131:203-210.

Moreau, P., Thoquet, P., Olivier, J., Laterrot, H., and Grimsley, N. 1998. Genetic mapping of $\mathrm{Ph}-2$, a single locus controlling partial resistance to Phytophthora infestans in tomato. Mol. Plant-Microbe Interact. 11:259-269.

Nowicki, M., Foolad, M. R., Nowakowska, M., and Kozik, E. U. 2012. Potato and tomato late blight caused by Phytophthora infestans: An overview of pathology and resistance breeding. Plant Dis. 96:4-17.

Ohlson, E. W., and Foolad, M. R. 2016. Genetic analysis of resistance to tomato late blight in Solanum pimpinellifolium accession PI163245. Plant Breed. 135:391-398.

Panthee, D. R., and Gardner, R. G. 2010. 'Mountain Merit': A late blight-resistan large-fruited tomato hybrid. HortScience 45:1547-1548.

Peirce, L. C. 1971. Linkage tests with $P h$ conditioning resistance to race 0 Phytophthora infestans. Tomato Genet. Coop. Rep. 21:30.

Robbins, M. D., Masud, M. A. T., Panthee, D. R., Gardner, R. G., Francis, D. M. and Stevens, M. R. 2010. Marker-assisted selection for coupling phase resistance to Tomato spotted wilt virus and Phytophthora infestans (late blight) in tomato. HortScience 45:1424-1428.

Rodewald, J., and Trognitz, B. 2013. Solanum resistance genes against Phytophthora infestans and their corresponding a virulence genes. Mol. Plant Pathol. 14:740-757.

Small, I. M., Joseph, L., and Fry, W. E. 2015. Evaluation of the Blight Pro decision support system for management of potato late blight using computer simulation and field validation. Phytopathology 105:1545-1554.

Smart, C. D., Tanksley, S. D., Mayton, H., and Fry, W. E. 2007. Resistance to Phytophthora infestans in Lycopersicon pennellii. Plant Dis. 91:1045 1049.

Van Ooijen, J. W. 2006. JoinMap 4: Software for the Calculation of Genetic Linkage Maps in Experimental Populations of Diploid Species. Kyazma BV, Wageningen, The Netherlands.

$\mathrm{Xu}$, J., and Jin, L. 2017. Advances and perspectives in research of potato genetics and breeding. Sci. Agric. Sin. 50:990-1015 (in Chinese).

Yue, J. X., Meyers, B. C., Chen, J. Q., Tian, D. C., and Yang, S. H. 2012. Tracing the origin and evolutionary history of plant nucleotide-binding site-leucine-rich repeat (NBS-LRR) genes. New Phytol. 193:1049-1063.

Zhang, C., Liu, L., Wang, X., Vossen, J., Li, G., Li, T., Zheng, Z., Gao, J., Guo, Y., Visser, R. G. F., Li, J., Bai, Y., and Du, Y. 2014. The Ph-3 gene from Solanum pimpinellifolium encodes CC-NBS-LRR protein conferring resistance to Phytophthora infestans. Theor. Appl. Genet. 127:1353-1364.

Zhang, C., Liu, L., Zheng, Z., Sun, Y., Zhou, L., Yang, Y., Cheng, F., Zhang, Z. Wang, X., Huang, S., Xie, B., Du, Y., Bai, Y., and Li, J. 2013. Fine mapping of the $P h-3$ gene conferring resistance to late blight (Phytophthora infestans) in tomato. Theor. Appl. Genet. 126:2643-2653. 